\title{
Donor for Cardiac Transplant
}

National Cancer Institute

\section{Source}

National Cancer Institute. Donor for Cardiac Transplant. NCI Thesaurus. Code C99947.

The subject contributing a heart for a cardiac transplant. (ACC) 